\title{
Luteolin inhibits angiogenesis of the M2-like TAMs via the downregulation of hypoxia inducible factor-1 $\alpha$ and the STAT3 signalling pathway under hypoxia
}

\author{
BINBO FANG ${ }^{1,2 *}$, XUEHAI CHEN ${ }^{2 *}$, MINMIN WU $^{2}$, HONGRU KONG $^{2}$, GUANYU CHU $^{2}$, \\ ZHENXU ZHOU ${ }^{2}$, CHUNWU ZHANG ${ }^{2}$ and BICHENG CHEN ${ }^{2}$ \\ ${ }^{1}$ Department of Surgery, The Affiliated Wenling Hospital of Wenzhou Medical University, Taizhou, Zhejiang 325000; \\ ${ }^{2}$ Zhejiang Provincial Top Key Discipline in Surgery, Wenzhou Key Laboratory of Surgery, The First Affiliated Hospital of \\ Wenzhou Medical University, Wenzhou, Zhejiang 325000, P.R. China
}

Received August 15, 2017; Accepted January 15, 2018

DOI: $10.3892 / \mathrm{mmr} .2018 .9250$

\begin{abstract}
The imbalance between angiogenic inducers and inhibitors appears to be a critical factor in tumour pathogenesis. Angiogenesis serves a key role in the occurrence, invasion and metastasis of tumours. Macrophages are a major cellular component of human and rodent tumours, where they are usually termed tumour-associated macrophages (TAMs). In malignant tumours, TAMs tend to resemble alternatively activated macrophages (M2-like), promote TA angiogenesis, strengthen tumour migration and invasive abilities, and simultaneously inhibit antitumor immune responses. In our previous study, luteolin, commonly found in a wide variety of plants, had a strong antitumor effect under normoxia; however, it is unknown whether luteolin serves a similar role under hypoxia. In the present study, cobalt chloride $\left(\mathrm{CoCl}_{2}\right)$ was used to simulate hypoxia. Hypoxia-inducible factor- $1 \alpha$ (HIF-1 $\alpha$ ), which is difficult to detect under normoxic conditions, was significantly increased. Additionally, vascular endothelial growth factor (VEGF) was also significantly increased in response to $\mathrm{CoCl}_{2}$ treatment. Subsequently, luteolin was applied with $\mathrm{CoCl}_{2}$ to examine the effects of luteolin. Luteolin decreased the expression of VEGF and matrix metalloproteinase-9, which promote angiogenesis. In addition, luteolin also suppressed the activation of HIF-1 and phosphorylated-signal transducer and activator of transcription 3 (STAT3) signalling, particularly within the M2-like TAMs. The results of the present study
\end{abstract}

Correspondence to: Dr Bicheng Chen, Zhejiang Provincial Top Key Discipline in Surgery, Wenzhou Key Laboratory of Surgery, The First Affiliated Hospital of Wenzhou Medical University, 2 Fuxue Lane, Wenzhou, Zhejiang 325000, P.R. China

E-mail: bisonch@163.com

*Contributed equally

Key words: luteolin, hypoxia, hypoxia inducible factor-1 $\alpha$, vascular endothelial growth factor, signal transducer and activator of transcription 3 , angiogenesis provide novel evidence that luteolin, under hypoxic conditions, has a strong anticancer effect via the HIF-1 $\alpha$ and STAT3 signalling pathways.

\section{Introduction}

Neighbouring normal cells are recruited by cancer cells to perform tumour processes. Thus, the study of cancer requires not only the focus on tumour cell activity, but to also evaluate the activity of the neighbouring normal cells (1). Macrophages are the most abundant non-tumour cell in cancers (2). Plasticity and flexibility are key features of macrophages because their cytokine production responds to specific environmental cues $(3,4)$. According to their functional properties, previous studies proposed the concept of macrophage polarization $(1,5)$. There are two phenotypes of polarized macrophages: M1 (classical) and M2 (alternative) macrophages. M1 macrophages, also termed classically-activated macrophages, which exhibit a strong proinflammatory and pathogen-killing effect in tissues. They are characterized by the production of destructive free radicals and inflammatory cytokines (6). M2 macrophages, which are also alternatively called activated macrophages, serve a role in immunoregulation, tissue remodelling and angiogenesis. It is now generally accepted that tumour-associated macrophages (TAMs) have an M2 phenotype and have the ability to promote tumour growth, migration, invasion and metastasis in various cancers (7-9). Therefore, the examination of TAMs may be a valuable addition to standard of care therapies.

Without vascular proliferation, tumour growth is restricted. Therefore, the process of angiogenesis is important for the growth and metastasis of tumors (10). Endothelial cell proliferation, migration and extracellular matrix decomposition are the three main stages of new blood vessel formation. This process is regulated by angiogenic factors, which are released from host cells and tumour cells, and is controlled by positive and negative regulatory factors. These vascular factors interact with receptors in the vicinity of blood vessels and induce endothelial cell activation, proliferation and migration towards the tumour. Inhibiting angiogenesis is an effective method for treating cancer. 
The tumour microenvironment is a special environment that is formed by the interaction of tumour cells, stromal cells and extracellular matrix. During the progression of numerous malignant tumours, hypoxia is one of the most common microenvironmental conditions and it may stimulate the expression of vascular endothelial growth factor (VEGF) (11). Hypoxia-inducible factor- $1 \alpha$ (HIF-1 $\alpha$ ) is a key protein upregulated by hypoxia. HIF-1 $\alpha$ regulates the expression of VEGF at the gene level and influences tumour development. Signal transducer and activator of transcription 3 (STAT3) is an important component of the signal transducer and activator of transcription family of proteins. STAT3 was initially identified as a component of the interleukin (IL)-6/Janus kinase signalling pathway and was confirmed to participate in numerous physiological processes, including cell proliferation, apoptosis and differentiation (12). Its role in the development of cancer should not be overlooked.

Numerous medicinal plants or chemical substances extracted from plants are potential anti-vascular drugs. Flavonoids have been reported to affect the initiation and development of tumours. Luteolin, a common dietary flavonoid, is found in fruits, vegetables and herbs. This compound has a variety of functions that induce anti-tumour effects, including the inhibition of tumour cell proliferation and the promotion of tumour cell apoptosis (13). However, the mechanisms by which luteolin exerts its effects on angiogenesis and on M2-like TAMs, under hypoxic conditions, are unclear. In the present study, a chemical hypoxic model was established using $\mathrm{CoCl}_{2}$ (14) to investigate whether hypoxia promotes the expression of HIF-1 $\alpha$ and VEGF in M2-like TAMs. Furthermore, by culturing cells in the presence of $\mathrm{CoCl}_{2}$ and luteolin, under hypoxic conditions, the present study investigated whether luteolin has an anti-cancer role via M2-like TAMs.

\section{Materials and methods}

Reagents. Luteolin (Sichuan Chengdu Mansite Biotechnology Co. Ltd., Sichuan China) was stored at $-4^{\circ} \mathrm{C}$ and dissolved in dimethyl sulfoxide prior to use. Cobalt chloride $\left(\mathrm{CoCl}_{2}\right)$ was obtained from Sigma-Aldrich (Merck-KGaA, Darmstadt, Germany) and IL-4 was from PeproTech EC Ltd (London, UK). Foetal bovine serum (FBS) was purchased from Sigma-Aldrich (Merck KGaA, Darmstadt, Germany). Trypsin and Dulbecco's modified Eagle's medium (DMEM) were purchased from Gibco (Thermo Fisher Scientific, Inc., Waltham, MA, USA). Anti-HIF-1 $\alpha$ (cat. no. ab113642), anti-VEGF (cat. no. ab69479), anti-MMP9 (cat. no. ab38898) and anti-tissue inhibitor of metalloproteinase 1 (TIMP1) antibodies (cat. no. ab38978) were purchased from Abcam (Cambridge, MA, USA). The anti- $\beta$-actin antibody (cat. no. ap0731) was purchased from Bioworld Technology Inc. (St. Louis Park, MN, USA). Antibodies against STAT3 (cat. no. 12640) and phosphorylated (p)-STAT3 (cat. no. 9145) were obtained from Cell Signaling Technology, Inc. (Danvers, MA, USA).

Cell culture. The mouse macrophage cell line RAW264.7 was obtained from The Cell Bank of Type Culture Collection of the Chinese Academy of Sciences (KCB200603YJ, Shanghai, China). Cells were cultured in DMEM with $10 \%$ FBS,
$100 \mathrm{U} / \mathrm{ml}$ penicillin and $100 \mu \mathrm{g} / \mathrm{ml}$ streptomycin in a $5 \% \mathrm{CO}_{2}$ incubator at $37^{\circ} \mathrm{C}$. When the cells were $\sim 80 \%$ confluent, trypsin containing $0.25 \%$ EDTA was used to detach the cells from the plates to proceed with the specific experimental treatments.

Induced polarization. To induce the polarization of macrophages into M2-like TAMs, the cells were treated with IL-4 $(10 \mathrm{ng} / \mathrm{ml})$ for $2 \mathrm{~h}$ at $37^{\circ} \mathrm{C}$. Macrophages and M2-like TAMs were used for the following experiments.

Cell viability assay. A Cell Counting Kit-8 (CCK8, Dojindo Molecular Technologies, Inc., Kumamoto, Japan) was used to detect whether varying concentrations of $\mathrm{CoCl}_{2}(25,50$, $100,150,200,250,300$ or $600 \mu \mathrm{M})$ and luteolin $(5,10,20$, $30,40,60,80$ or $160 \mu \mathrm{M})$ affected the survival rate of mouse macrophages. Cells $\left(1 \times 10^{4}\right)$ were plated in 96 -well plates, and at $\sim 70 \%$ confluence, the medium was replaced with serum-free DMEM for $12 \mathrm{~h}$. A total of $10 \mu \mathrm{l}$ of CCK8 solution was added to each well following incubation with various concentrations of $\mathrm{CoCl}_{2} /$ luteolin for $24 \mathrm{~h}$ at $37^{\circ} \mathrm{C}$. After $2 \mathrm{~h}$, a microplate reader was used to measure the absorbance of each well at $450 \mathrm{~nm}$.

Cell invasion and migration assays. First, to polarize macrophages to M2-like TAMs, when cells were $\sim 80-90 \%$ confluent, the cells were treated with IL-4 for $2 \mathrm{~h}$ at $37^{\circ} \mathrm{C}$. Then, the macrophages and TAMs were used for the following experiments. To test cell invasion and migration, Transwell filter chambers (Corning, Inc., Corning, NY, USA) were used with an $8-\mu \mathrm{m}$ pore size, which were coated with or without Matrigel basement membrane matrix (Corning, Inc.). In the invasion assays, $100 \mu \mathrm{l}$ serum-free DMEM with $5 \times 10^{4}$ cells was added to the upper chamber, and $600 \mu \mathrm{l}$ DMEM with $10 \%$ FBS was added to the lower Transwell chamber. Conversely, for the migration assays, $100 \mu 1$ serum-free DMEM with $5 \times 10^{3}$ cells was added to the upper chamber, and $600 \mu 1$ DMEM with $10 \%$ FBS was placed in the lower chamber. Following the addition of $\mathrm{CoCl}_{2}(100 \mu \mathrm{M})$ or luteolin $(20 \mu \mathrm{M})$, the cells were placed in in a $5 \% \mathrm{CO}_{2}$ incubator for $24 \mathrm{~h}$ at $37^{\circ} \mathrm{C}$. Subsequently, the cells were washed three times with $\mathrm{PBS}$, and the chambers were soaked in $4 \%$ paraformaldehyde for $30 \mathrm{~min}$ at room temperature. Following three washes with PBS, the cells were stained with haematoxylin for $20 \mathrm{~min}$ at room temperature. Finally, an inverted microscope at magnification of x200 was used to observe and count the stained cells by randomly selecting 10 fields of view.

Reverse transcription-quantitative polymerase chain reaction ( $q P C R)$. First, cells were treated with IL-4 for $2 \mathrm{~h}$ at $37^{\circ} \mathrm{C}$ to polarize macrophages into M2-like TAMs. When cells were 80-90\% confluent, the cells were then cultured with $\mathrm{CoCl}_{2}$ $(100 \mu \mathrm{M})$ for $2 \mathrm{~h}$ and with luteolin $(20 \mu \mathrm{M})$ for $24 \mathrm{~h}$. TRIzol reagent (Thermo Fisher Scientific, Inc.) was used to extract total RNA according to the manufacturer's protocols. The quantitative analysis of $\beta$-actin, MMP9, VEGF and TIMP1 expression was performed using a Fast Start Universal SYBR Green Master kit (ROX; Roche Diagnostics, Basel, Switzerland) on a 7500 Real-Time PCR system (Applied Biosystems; Thermo Fisher Scientific, Inc.). The reactions were then subjected to the following temperature protocol: Stage $1,95^{\circ} \mathrm{C}$ for $3 \mathrm{~min}$; 
Table I. Primers used in reverse transcription-quantitative polymerase chain reaction.

\begin{tabular}{lll}
\hline Gene & \multicolumn{1}{c}{ Sense $\left(5^{\prime}-3^{\prime}\right)$} & \multicolumn{1}{c}{ Antisense (5'-3') } \\
\hline VEGF & ACTTTCTGCTCTCTTGGGT & GACTTCTGCTCTCCTTCTGT \\
MMP9 & TACGATAAGGACGGCAAA & CAAAGATGAACGGGAACA \\
TIMP1 & TCTGGCATCCTCTTGTTG & GGTGGTCTCGTTGATTTCT \\
$\beta$-actin & GGGAAATCGTGCGTGAC & AGGCTGGAAAAGAGCCT
\end{tabular}

MMP9, matrix metalloproteinase 9; TIMP1, tissue inhibitor of metalloproteinase 1; VEGF, vascular endothelial growth factor.

stage $2,95^{\circ} \mathrm{C}$ for $15 \mathrm{sec}$ and $60^{\circ} \mathrm{C}$ for $1 \mathrm{~min}$ for 40 cycles, and stage $3,95^{\circ} \mathrm{C}$ for $15 \mathrm{sec}, 60^{\circ} \mathrm{C}$ for $1 \mathrm{~min}, 95^{\circ} \mathrm{C}$ for $15 \mathrm{sec}$ and $60^{\circ} \mathrm{C}$ for $15 \mathrm{sec}$. Finally, the $2^{-\Delta \Delta \mathrm{Cq}}$ method (15) was to calculate the relative expression of the target gene for the analysis. The details: $\Delta \Delta \mathrm{Cq}=\left(\mathrm{Cq}_{\text {experimental group target gene }}-\mathrm{Cq}_{\text {experimental group }}\right.$ $\beta$-actin gene $)-\left(\mathrm{Cq}_{\text {control group target gene }}-\mathrm{Cq}_{\text {control group } \beta \text {-actin gene }}\right)$. The qPCR primers were purchased from Synbio-Tech (Jiangsu, China), and their sequences are listed in Table I.

Western blot analysis. Following the aforementioned treatments, at $80-90 \%$ confluence, total proteins were extracted from the cells. Radioimmunoprecipitation assay lysate buffer (Beyotime Institute of Biotechnology, Shanghai, China) with $10 \%$ phosphatase inhibitors (Roche Diagnostics $\mathrm{GmbH}$, Mannheim, Germany) and 1\% PMSF (Beyotime Institute of Biotechnology). A Bicinchoninic Acid kit (Beyotime Institute of Biotechnology) was used to determine the protein concentration. Then, $50 \mu \mathrm{g}$ protein was dissolved in loading buffer containing SDS and was heated for $5 \mathrm{~min}$ at $100^{\circ} \mathrm{C}$. Following denaturation, $10 \%$ SDS-PAGE was used to isolate the proteins, which were transferred onto polyvinylidene fluoride (PVDF) membranes via wet blotting transfer. The PVDF membranes were incubated with tris-buffered saline and Tween-20 (TBST) with $5 \%$ skim milk for $1.5 \mathrm{~h}$ at room temperature. Various antibodies at different dilutions (HIF-1 $\alpha$, VEGF, MMP9, TIMP1, STAT3 and p-STAT3 all 1:1,000 and $\beta$-actin 1:10,000) were incubated with the membranes overnight at $4^{\circ} \mathrm{C}$. Following three washes with TBST, the membranes were incubated with horseradish peroxidase-conjugated secondary antibodies (goat anti-rabbit immunoglobulinG $(\mathrm{H}+\mathrm{L})$-horseradish peroxidase; 1:10,000; cat. no. BS13278, Bioworld Technology, Inc.) for $1.5 \mathrm{~h}$ at room temperature. Enhanced chemiluminescence was used to detect and image the bands with a Bio-Rad gel imaging system (version 5.1, Bio-Rad Laboratories, Inc., Hercules, CA, USA) or with X-ray film.

Immunofluorescence staining. Following the aforementioned treatments, cells were washed with PBS and fixed in $4 \%$ paraformaldehyde for $15 \mathrm{~min}$ at $4^{\circ} \mathrm{C}$ Then, the cells were permeabilized with $0.5 \%$ Triton $\mathrm{X}-100$ for $10 \mathrm{~min}$ and blocked with PBS containing 10\% goat serum (Beyotime Institute of Biotechnology) for $1 \mathrm{~h}$ at room temperature. Subsequently, the cells were incubated with anti-VEGF antibody $(1: 200)$ at $4^{\circ} \mathrm{C}$ overnight. Following three washes with PBS, the cells were incubated with a secondary antibody conjugated with Alexa Fluor 488 (1:200; cat. no. A-11034; Thermo Fisher Scientific, Inc.) at room temperature for $1 \mathrm{~h}$. Following three washes with
PBS, DAPI was used to stain the cell nuclei for $5 \mathrm{~min}$ at room temperature. Finally, the glass slides were photographed using an automated upright microscope system with anti-fluorescence quenching (magnification, $\mathrm{x} 400$ ).

Statistical analysis. All analyses were performed using SPSS version 19.0 software (IBM Corp., Armonk, NY, USA). The results are expressed as the means \pm standard deviation of multiple experiments or representative images. One-way analysis of variance followed by Tukey's Multiple Comparison test) was used to assess significance when evaluating the statistical correlation of data between groups. $\mathrm{P}<0.05$ was considered to indicate a statistically significant difference; all experiments were repeated three times.

\section{Results}

Effect of luteolin or $\mathrm{CoCl}_{2}$ on cell survival rate and the impact of $\mathrm{CoCl}_{2}$ on the expression of HIF-1 $\alpha$ and VEGF. A CCK8 assay was used to investigate the effect of various concentrations of luteolin and $\mathrm{CoCl}_{2}$ on cell survival rate. In the CCK8 experimental results with luteolin treatment only, the cell survival rate was not significantly reduced following treatment with 5,10 or $20 \mu \mathrm{M}$ of luteolin (Fig. 1A). However, upon treatment with $>20 \mu \mathrm{M}$ luteolin, the cell survival rate was significantly decreased. The CCK8 experimental results with $\mathrm{CoCl}_{2}$ treatment confirmed that $100 \mu \mathrm{M} \mathrm{CoCl}_{2}$ did not significantly decrease the cell survival rate (Fig. 1B). However, concentrations of $\mathrm{CoCl}_{2} \geq 150 \mu \mathrm{M}$ caused a significant decline in the cell survival rate. At these concentrations, $\mathrm{CoCl}_{2}$ led to a substantial increase in macrophage death. Therefore, the expression of VEGF and HIF-1 $\alpha$ was used to evaluate the efficacy of the hypoxic environment induced by $\mathrm{CoCl}_{2}$. The western blotting results demonstrated that HIF-1 $\alpha$ expression was low in the normal group. However, when the concentration of $\mathrm{CoCl}_{2}$ was increased, the expression of HIF-1 $\alpha$ also increased; the same result was observed for the protein and mRNA expression of VEGF (Fig. 1C and D). Treatment with $200 \mu \mathrm{M} \mathrm{CoCl}_{2}$ did not markedly increase the expression of these proteins. These results indicated that $\mathrm{CoCl}_{2}(100 \mu \mathrm{M})$ effectively induced a hypoxic environment and provided appropriate conditions for the following experiments. A total of $20 \mu \mathrm{M}$ luteolin and $100 \mu \mathrm{M} \mathrm{CoCl}_{2}$ were used for subsequent experiments.

Effects of luteolin on invasion and migration. Transwell invasion and migration assays were used to detect the effect of 
A
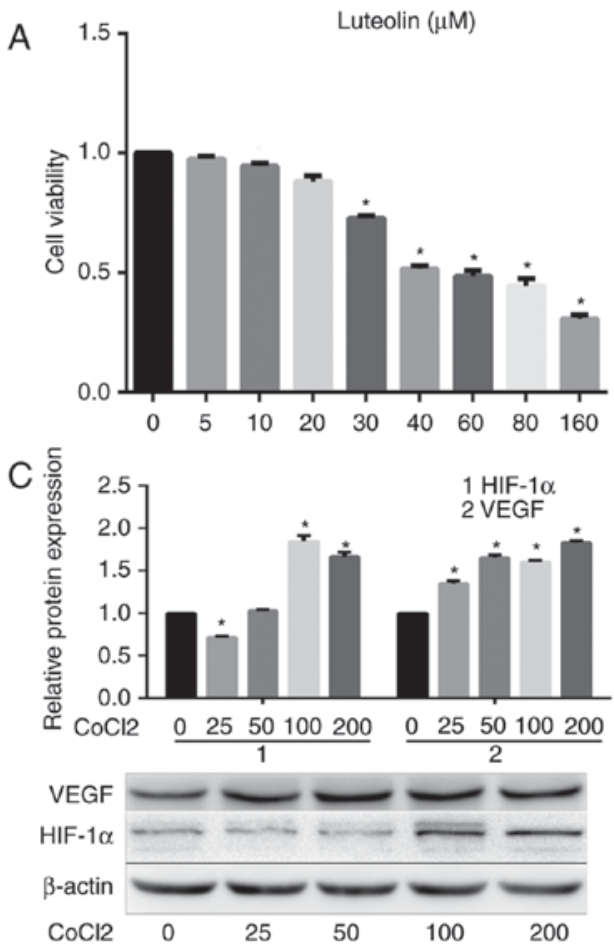

B

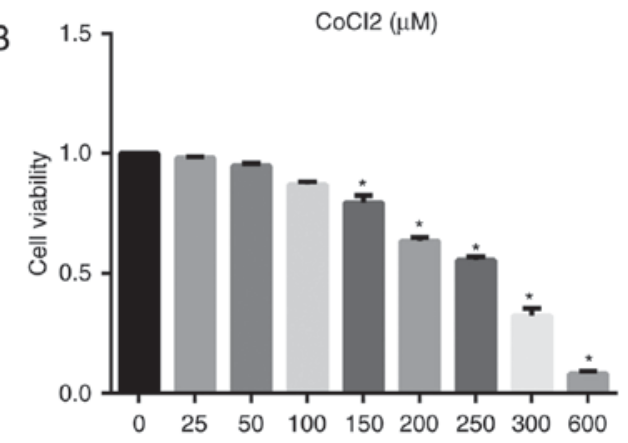

D

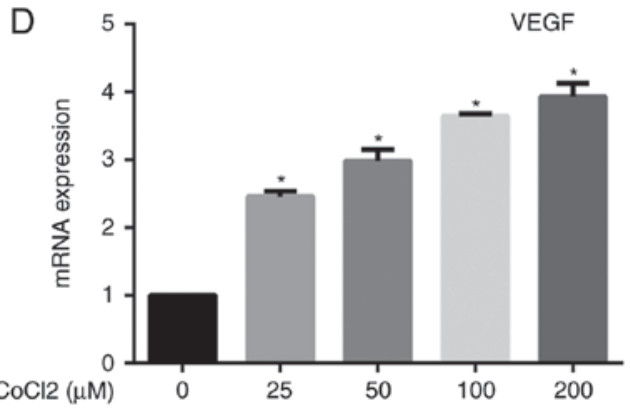

Figure 1. Cell Counting kit-8 toxicity assay and the effect of $\mathrm{CoCl}_{2}$ on HIF-1 $\alpha$ and VEGF expression. (A) RAW264.7 cells were treated with various concentrations of luteolin as indicated. (B) RAW264.7 cells were treated with various concentrations of $\mathrm{CoCl}_{2}$ as indicated. (C) Expression of $\mathrm{HIF}-1 \alpha$ protein was analysed by western blotting. (D) VEGF mRNA expression was determined using reverse transcription-quantitative polymerase chain reaction. ${ }^{*} \mathrm{P}<0.05$, compared with the untreated control group. HIF-1 $\alpha$, hypoxia-inducible factor-1 $\alpha$; VEGF, vascular endothelial growth factor.

luteolin on cell invasion and migration. Following the addition of IL-4 the invasive ability of the cells was increased. Under the hypoxic environment, the invasion ability of M2-like TAMs was greater than that of the macrophages, which was consistent with the MMP9 expression results from western blotting described below. However, following treatment with luteolin, the invasive capability of these two cell types was significantly weakened, particularly that of the M2-like TAMs (Fig. 2A and C). In addition, in the migration experiment, the number of M2-like TAMs was significantly lower than the number of macrophages untreated with IL-4. The migration ability of the cells was also significantly inhibited following treatment with luteolin, particularly in the M2-like TAMs treated with IL-4 (Fig. 2B and D). Therefore, the results of the present study indicated that luteolin may inhibit M2-like TAM and macrophage invasion and migration, particularly in the M2-like TAMs.

Under hypoxic conditions, luteolin regulates angiogenesis. As hypoxic environments promote angiogenesis, the ability of M2-like TAMs to promote angiogenesis was increased compared with that of macrophages in a hypoxic environment. VEGF and MMP9 are the main factors that promote angiogenesis (16-18). The expression levels of VEGF and MMP9 were higher within M2-like TAMs than in macrophages, as presented by western blotting and PCR experiments (Fig. 3A-D). However, following treatment with luteolin $(20 \mu \mathrm{M})$, the expression levels of VEGF and MMP9 were significantly decreased. In addition, the expression of TIMP1, a biological inhibitor of MMP9, was increased when cells were treated with luteolin (20 $\mu \mathrm{M}$; Fig. 3E and F). Immunofluorescence also revealed that the expression of VEGF was lower in macrophages than in
M2-like TAMs (Fig. 4A). The expression of VEGF was inhibited following the addition of luteolin, which was consistent with the PCR and western blotting results. Therefore, luteolin may inhibit the ability of macrophages and M2-like TAMs in particular, to promote angiogenesis.

Under hypoxia, luteolin regulates the HIF-1 $\alpha$ and STAT3 signalling pathways. There is a close association between angiogenesis and the STAT3 and HIF-1 $\alpha$ signalling pathways: Both pathways have been previously reported to contribute to the formation of blood vessels $(16,19)$. In the hypoxic environment of the present study, the ability of M2-like TAMs to promote angiogenesis was confirmed by the activation of the HIF-1 $\alpha$ and p-STAT3 signalling pathways (Fig. 4B and C). The present study demonstrated via western blotting that STAT3 expression was not significantly different among the groups. This indicated that within M2-like TAMs, the STAT3 signalling pathway may have served an angiogenic role via the phosphorylation of STAT3 rather than by an increase in STAT3 expression. Following treatment with luteolin $(20 \mu \mathrm{M})$, the expression of HIF-1 $\alpha$ and p-STAT3 was significantly reduced, possibly inhibiting the expression of angiogenic factors, such as VEGF and MMP9. These data indicated that under hypoxic environments, luteolin may mainly have an anti-angiogenic role via the inhibition of the HIF- $1 \alpha$ and p-STAT3 signalling pathways, particularly within the M2-like TAMs.

\section{Discussion}

Angiogenesis occurs due to the proliferation of tumour cells, which causes an increased demand for nutrients and 

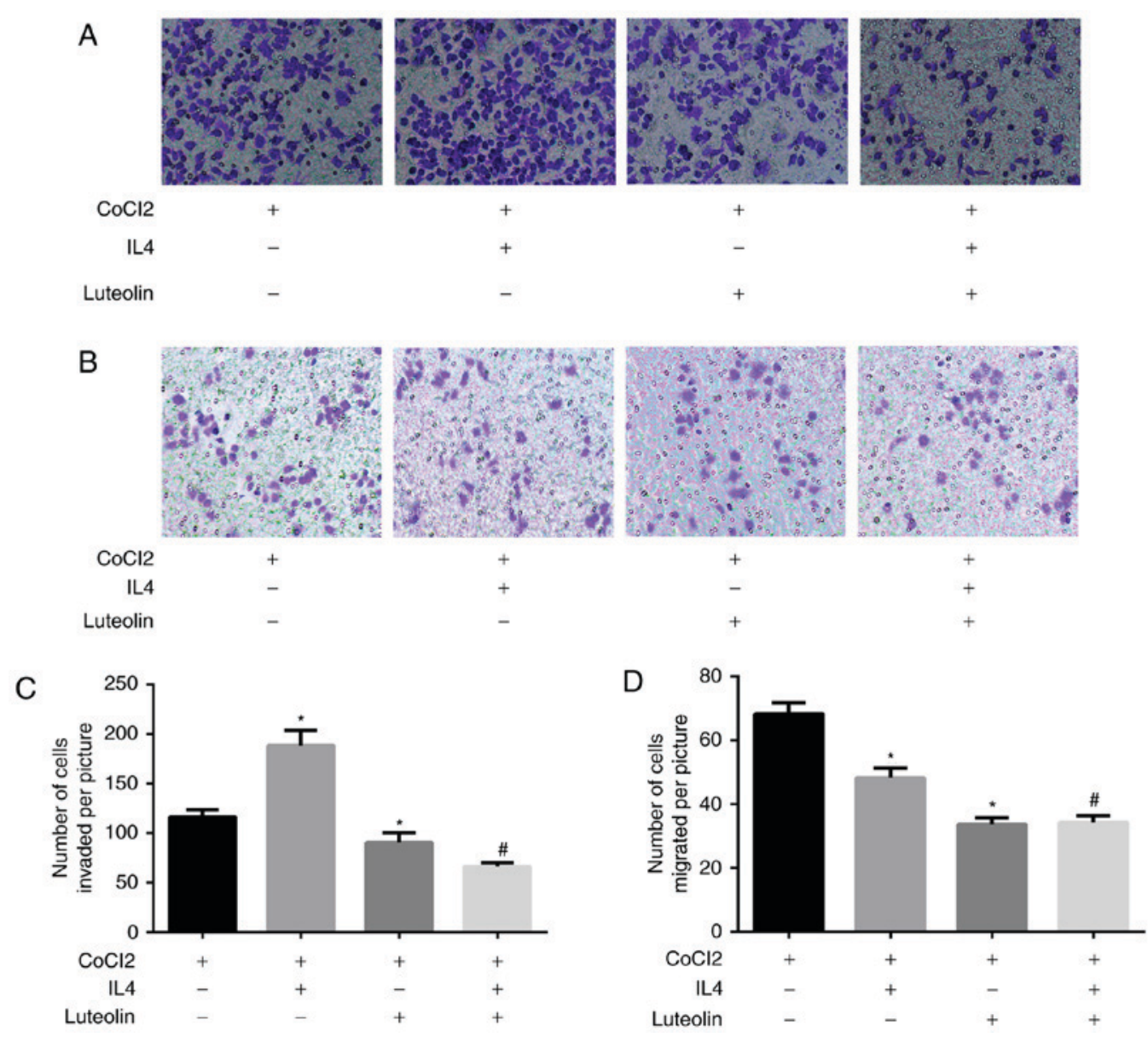

Figure 2. Effects of luteolin on invasion and migration. (A) Representative images of RAW264.7 cells in invasion experiments. Magnification, x200. (B) Representative images of RAW264.7 cells in migration experiments. Magnification, $\mathrm{x} 200$. (C and D) Cells counted in the Transwell image fields. " $\mathrm{P}<0.05$, vs. the hypoxia group; ${ }^{*} \mathrm{P}<0.05$, compared with the group induced with IL-4 and not with luteolin. IL-4, interleukin- 4 .

oxygen (20). Angiogenesis has an essential role in tumour processes, including migration, metastasis and growth and is regulated by pro-angiogenic and anti-angiogenic factors (21). The process of angiogenesis includes the activation, proliferation and migration of endothelial cells. In most malignant tumours, the factors that induce angiogenesis are increased; among these, VEGF is the most important (22). VEGF is a highly specific vascular endothelial cell mitogen that has an important role in physiological and pathological processes (22). VEGF exerts its biological effects by binding to the tyrosine kinase receptors expressed on endothelial cells. The VEGF receptor belongs to the tyrosine kinase family, and based on structure and function, this receptor is divided into three types: VEGFR1 (Flt21), VEGFR2 (KDR/Flk21) and VEGFR3 (Flk24) (23). VEGFR2 and VEGFR1 are mainly expressed on vascular endothelial cells and have an important role in the formation of blood vessels (24). Conversely, VEGFR3 is mainly expressed within lymphatic endothelial cells. VEGF achieves its effect by primarily interacting with VEGFR2 (25). VEGF binding to its receptor directly promotes endothelial cell mitosis, induces plasminogen degradation and leads to increased vascular permeability, inducing the exudation of plasma proteins, and thereby promoting the proliferation and migration of tumour vascular endothelial cells (22). A previous study demonstrated that higher levels of VEGF were associated with a greater probability of micrometastasis in liver cancer (26). VEGF activation leads to the activation of a series of signal transduction proteins, including extracellular signal-regulated kinase, protein kinase $\mathrm{B}$ and mechanistic target of rapamycin (mTOR) (27-29). These signal transduction proteins may promote the growth, migration, differentiation and proliferation of vascular endothelial cells. Previous studies have suggested that TAMs are involved in processes of a variety of different types of cancers (30). Thus, cancer progression may be suppressed by inhibiting M2-like TAMs (31). Previous epidemiological studies have indicated an association between increased macrophage infiltration and poor prognoses of ovarian, cervical, thyroid, lung and hepatocellular cancers (32-34). In addition, an increasing evidence suggests that M2-like TAMs have an important role in cancer progression and metastasis, establishing TAMs, M2-like TAMs in particular, as an appealing target for therapeutic interventions. Therefore, specifically affecting M2-like TAMs and reducing macrophage infiltration may effectively interfere with tumour progression. A previous study demonstrated that luteolin promotes apoptosis and inhibits cancer cell metastasis, thereby interfering with the progression of cancer (35). In the present study, mouse macrophages were used to investigate the potential anticancer effect of luteolin in hypoxic environments.

Due to the lack of hypoxia incubators, $\mathrm{CoCl}_{2}$ was used to mimic hypoxic conditions in the experiment design. A low-oxygen environment was simulated with $\mathrm{CoCl}_{2}$ treatment and the results revealed that in the presence of $\mathrm{CoCl}_{2}$, the 
A

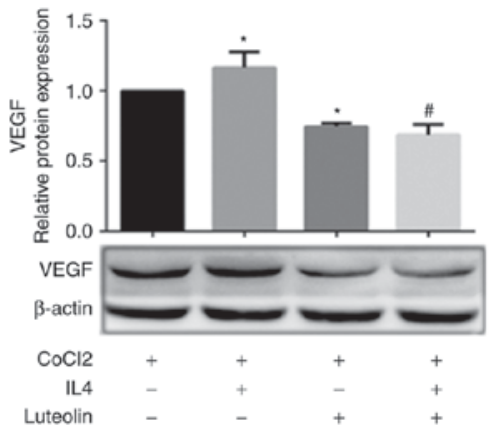

C

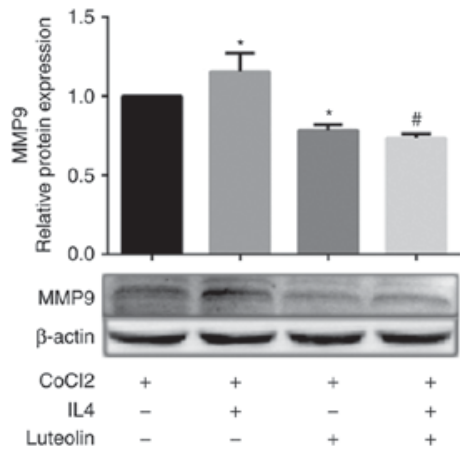

E

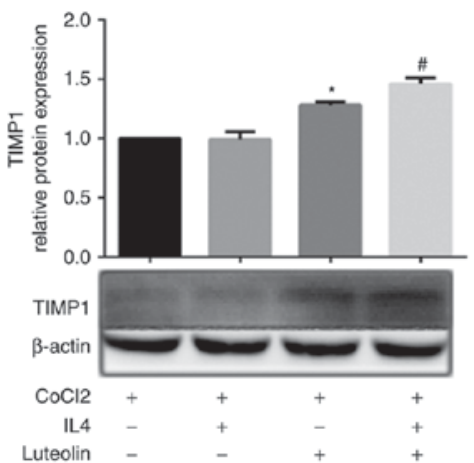

B
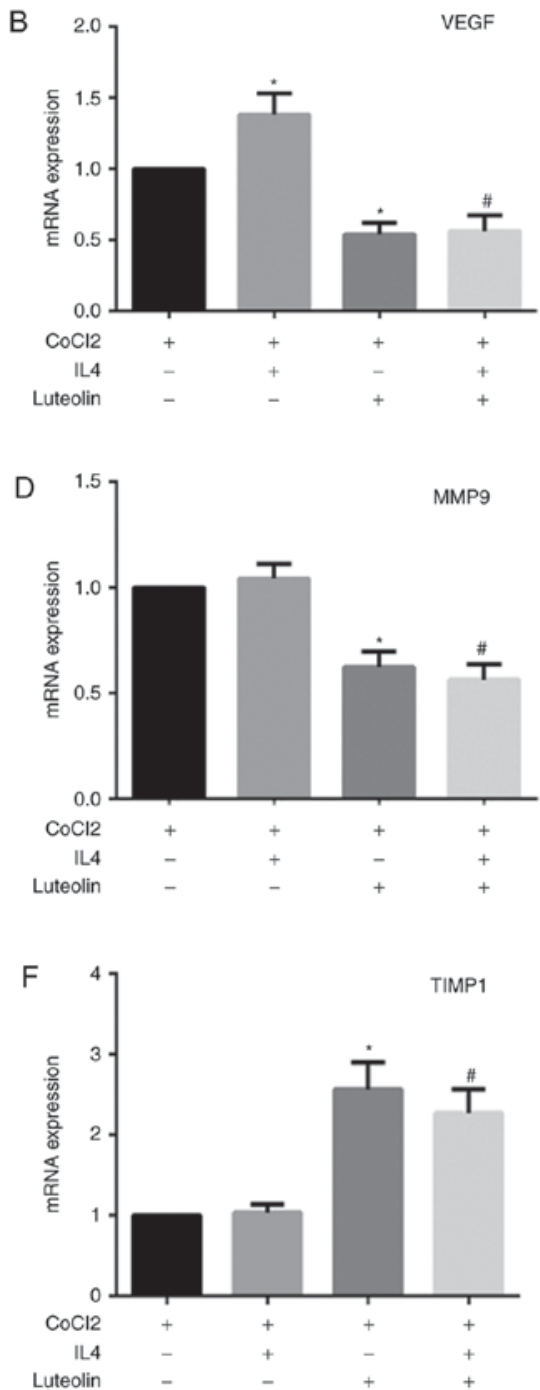

Figure 3. Effects of luteolin on angiogenesis in hypoxia. Expression levels of the VEGF protein and mRNA were analysed by (A) western blotting and (B) RT-qPCR, respectively. Expression levels of (C) MMP9 protein and (D) mRNA were analysed by western blotting and RT-qPCR, respectively. Expression of TIMP 1 (E) protein and (F) mRNA was analysed by western blotting and RT-qPCR. " $\mathrm{P}<0.05$, vs. the hypoxia group induced by $\mathrm{CoCl}_{2}$. $\mathrm{P}<0.05$ vs. the group induced with IL-4 and not with luteolin. IL-4, interleukin-4; MMP9, matrix metalloproteinase 9; RT-qPCR, reverse transcription-quantitative polymerase chain reaction; TIMP1, tissue inhibitor of metalloproteinase 1; VEGF, vascular endothelial growth factor.

expression levels of VEGF and HIF-1 $\alpha$ were increased. The results of the present study indicated that the treatment with $\mathrm{CoCl}_{2}$ successfully simulated low oxygen conditions. VEGF may promote the migration and invasion of tumour cells and the formation of tumour blood vessels, resulting in an increase in the degree of tumour malignancy (36). The results of western blotting, RT-qPCR and immunofluorescence experiments revealed that the expression of VEGF was increased in M2-like TAMs; however, the expression of VEGF was significantly inhibited following treatment with luteolin, particularly within the M2-like TAMs. VEGF has an important role in tumour angiogenesis, vascular permeability, tumour stem cell function and the occurrence and development of tumours (18). The finding that luteolin reduces the expression of VEGF of the present study, indicated that luteolin may have an anti-angiogenic role and inhibits tumour progression under hypoxic conditions.

In the formation of blood vessels, the first step is to degrade the extracellular matrix and basement membrane, conducted by MMPs, which belong to a family of endopeptidases (37). Degradation of the vascular basement membrane is an indispensable step for the invasion of endothelial cells. An increase in MMPs is associated with tumour invasion, metastasis and angiogenesis (38). Among the proteolytic enzymes, MMP9 has been reported both in vivo and in vitro, to have an important role in angiogenesis. In the present study, western blotting and RT-qPCR confirmed the increased expression of MMP9 within M2-like TAMs, which is conducive to tumour angiogenesis. However, following treatment with luteolin, the expression of MMP9 was significantly decreased; the expression of its inhibitor, TIMP1, was increased. This result suggested that the anti-angiogenic effect of luteolin may be achieved via the inhibition of VEGF and MMP9 expression.

The hypoxic environment simulated by $\mathrm{CoCl}_{2}$ significantly promoted the expression of HIF-1 $\alpha$, which was confirmed by western blotting. The protein expression level of HIF-1 $\alpha$ was increased in hypoxic conditions, mimicked by $\mathrm{CoCl}_{2}$, but no alterations in its mRNA expression level was observed (39). 
A

A
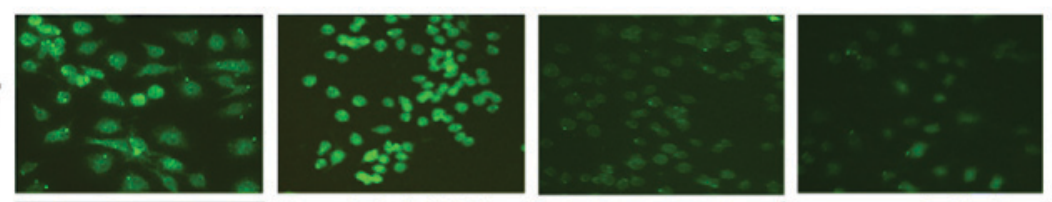

DAPI
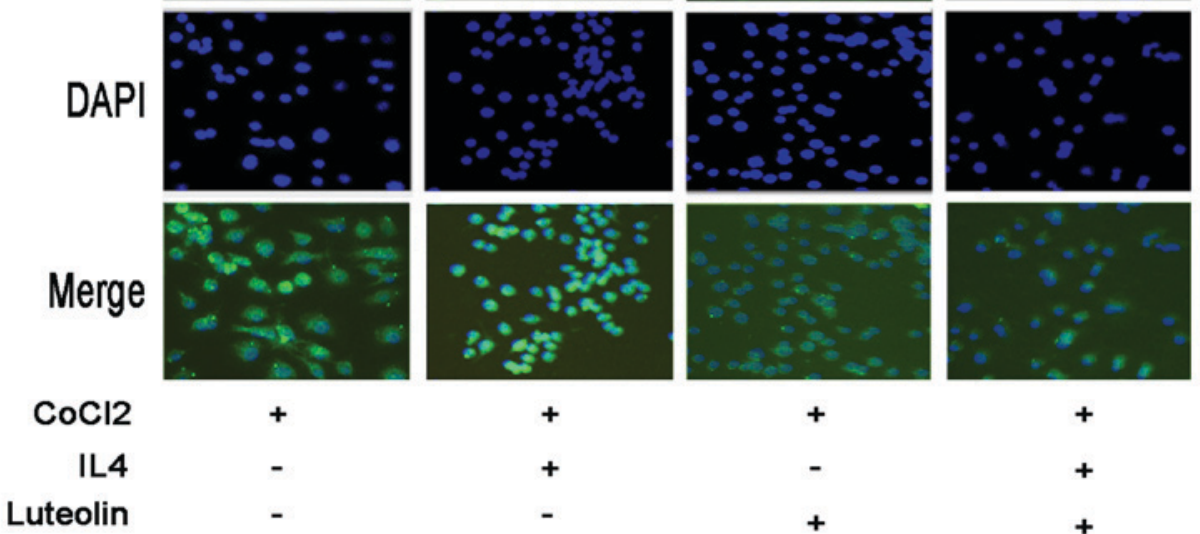

B
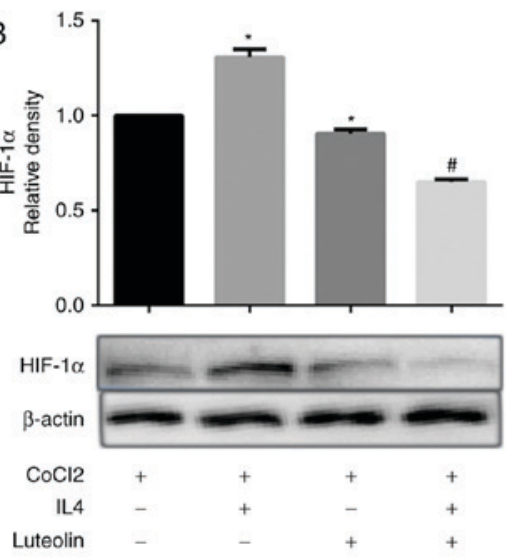

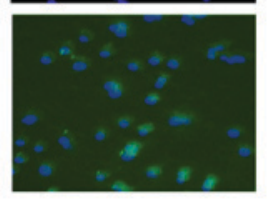

$+$

$+$

$+$
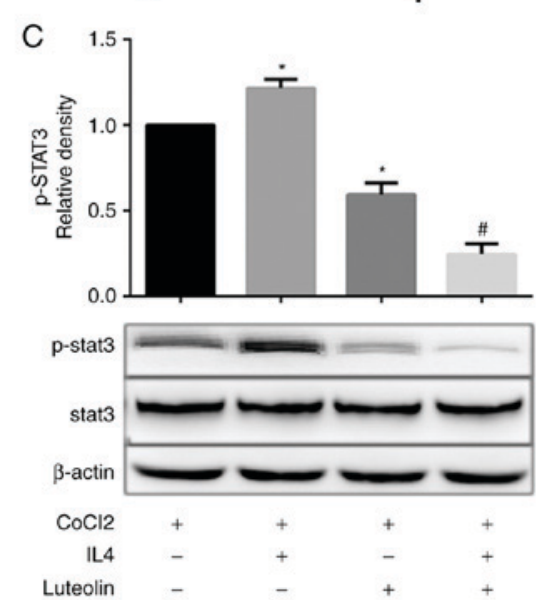

Figure 4. Effects of luteolin on VEGF expression under hypoxic conditions and the effects of luteolin on the HIF-1 $\alpha$ and STAT3 signalling pathways. (A) Expression of VEGF protein was analysed by immunofluorescence. (B) Expression of HIF-1 $\alpha$, (C) p-STAT3 and STAT3 protein was analysed by western blotting. " $\mathrm{P}<0.05$ vs. the hypoxia group induced by $\mathrm{CoCl}_{2} ;{ }^{*} \mathrm{P}<0.05$ vs. the group induced with IL- 4 and not with luteolin. HIF-1 $\alpha$, hypoxia-inducible factor- $1 \alpha$; IL-4, interleukin-4; p-STAT3, phosphorylated signal transducer and activator of transcription 3; VEGF, vascular endothelial growth factor.

A previous study reported that luteolin significantly inhibited the expression of ubiquitin E2S ligase, which regulates the expression of HIF-1 $\alpha$ (40). Another study demonstrated that luteolin may inhibit the activation of HIF-1, which may contribute to the inhibition of the mitogen-activated protein kinase pathway (41). In addition, the other major regulator in hypoxia is mTOR, which promotes HIF-1 $\alpha$ protein activation when hyperactivated $(42,43)$. A previous study indicated that luteolin may inhibit the activation of Mtor (44). Therefore, the negative effect of luteolin and HIF-1 $\alpha$ may contribute to the hyperactivation of mTOR. HIF-1 $\alpha$, a key regulator of hypoxia, initiates the gene expression of associated factors that contribute to angiogenesis, cell survival, invasion and migration (45). Research on effective HIF-1 $\alpha$ inhibitors has gained attention. It has been reported that HIF-1 $\alpha$ inhibitors may have potential novel anticancer drugs $(46,47)$. HIF-1 $\alpha$ may regulate the expression of VEGF and MMP9 and thereby contribute to the occurrence and development of tumours (48). However, the $\mathrm{CoCl}_{2}$-induced increase in HIF-1 $\alpha$ expression was inhibited by luteolin in the present study. The ability of luteolin to inhibit VEGF and MMP9 expression may be achieved via the regulation of HIF-1 $\alpha$. Therefore, luteolin may exert its anti-angiogenic effects via the HIF-1 $\alpha$-VEGF/MMP9 signalling pathway.

The STAT3 protein in the cytoplasm of normal cells has an important role in regulating cell growth and differentiation. STAT3 appears to be a nexus for numerous oncogenic signalling pathways. The STAT3 gene, located at 17q21.2, is considered a proto-oncogene, and p-STAT3 enters the nucleus and directly binds to DNA, thereby inducing downstream gene expression. Recently, many studies have shown that activated STAT3 upregulates the expression of VEGF and induces tumour angiogenesis $(26,36)$. Furthermore, previous studies have described STAT3 as a potential modulator of HIF-1 $\alpha$-induced VEGF signalling in cancer cells $(39,49)$. P-STAT3 is additional promoter of angiogenesis $(50,51)$. The activation of p-STAT3 was significantly inhibited by luteolin in M2-like TAMs. The STAT3 signalling pathway may be another mechanism luteolin uses to contribute to angiogenesis. The expression of HIF-1 $\alpha$ and VEGF was reduced concomitantly with the expression of p-STAT3 in the present study. This suggested that the STAT3 
signalling pathway may also be involved with the expression of HIF-1 $\alpha$, VEGF and MMP9 under hypoxic conditions. In addition, the reduced expression of VEGF and MMP9 due to luteolin may be the result of the combined action of HIF- $1 \alpha$ and MMP9. Under hypoxic conditions, luteolin may have an anti-angiogenic role, which may be achieved via the HIF-1 $\alpha$ and STAT3 signalling pathways; however, the association between STAT3 and HIF-1 $\alpha$ requires further investigation (39).

In summary, luteolin may inhibit the abilities of M2-like TAMs, which are induced by IL-4, to induce angiogenesis, thereby inhibiting tumour growth. In combination with previous research, luteolin may have a potent anticancer role, either under normoxic or hypoxic conditions. The use of luteolin may be a novel therapeutic strategy for targeting tumour invasion, migration, apoptosis and vessel generation. In conclusion, the development of novel luteolin-based drugs may be a new direction for anticancer research.

\section{Acknowledgements}

Not applicable.

\section{Funding}

The present study was sponsored by the National Health and Family Planning Commission of Zhejiang Province (grant nos. 2013ZDA014, 2014ZB073), National Natural Science of China (grant no. 81572087), Natural Science Foundation of Zhejiang Province (grant nos. LY2H05004, LY16H030013), and the Wenzhou Municipal Science and Bureau (grant nos. Y20140672, Y20150062).

\section{Availability of data and materials}

All data generated or analyzed during this study are included in this published article.

\section{Authors' contributions}

$\mathrm{BF}, \mathrm{XC}, \mathrm{MW}, \mathrm{HK}, \mathrm{GC}, \mathrm{ZZ}$ and $\mathrm{CZ}$ performed the experiments. $\mathrm{BF}$ and $\mathrm{XC}$ wrote the manuscript. $\mathrm{BC}, \mathrm{BF}$ and $\mathrm{XC}$ designed the experiments and analysed all data.

\section{Ethics approval and consent to participate}

Not applicable.

\section{Consent for publication}

Not applicable.

\section{Competing interests}

The authors declare that there are no competing interests.

\section{References}

1. Hanahan D and Coussens LM: Accessories to the crime: Functions of cells recruited to the tumor microenvironment Cancer Cell 21: 309-322, 2012.
2. Dannenmann SR, Thielicke J, Stöckli M, Matter C, von Boehmer L, Cecconi V, Hermanns T, Hefermehl L, Schraml P, Moch H, et al: Tumor-associated macrophages subvert T-cell function and correlate with reduced survival in clear cell renal cell carcinoma. Oncoimmunology 2: e23562, 2013.

3. Murray PJ and Wynn TA: Obstacles and opportunities for understanding macrophage polarization. J Leukoc Biol 89: 557-563, 2011.

4. Wynn TA, Chawla A and Pollard JW: Macrophage biology in development, homeostasis and disease. Nature 496: 445-455, 2013.

5. Mantovani A, Romero P, Palucka AK and Marincola FM: Tumour immunity: Effector response to tumour and role of the microenvironment. Lancet 371: 771-783, 2008.

6. Murray PJ, llen JE, Biswas SK, Fisher EA, Gilroy DW, Goerdt S, Gordon S, Hamilton JA, Ivashkiv LB, Lawrence T, et al: Macrophage activation and polarization: Nomenclature and experimental guidelines. Immunity 41: 14-20, 2014.

7. PickertG,LimHY, Weigert A,Häussler A, Myrczek T, Waldner M, Labocha S, Ferreirós N, Geisslinger G, Lötsch J, et al: Inhibition of GTP cyclohydrolase attenuates tumor growth by reducing angiogenesis and M2-like polarization of tumor associated macrophages. Int J Cancer 132: 591-604, 2013.

8. Cardoso AP, Pinto ML, Pinto AT, Oliveira MI, Pinto MT, Gonçalves R, Relvas JB, Figueiredo C, Seruca R, Mantovani A, et al: Macrophages stimulate gastric and colorectal cancer invasion through EGFR Y(1086), c-Src, Erk1/2 and Akt phosphorylation and smallGTPase activity. Oncogene 33: 2123-2133, 2014.

9. Chen W, Ma T, Shen XN, Xia XF, Xu GD, Bai XL and Liang TB: Macrophage-induced tumor angiogenesis is regulated by the TSC2-mTOR pathway. Cancer Res 72: 1363-1372, 2012.

10. Bellon G, Martiny L and Robinet A: Matrix metalloproteinases and matrikines in angiogenesis. Crit Rev Oncol Hematol 49: 203-220, 2004

11. Li SH, Shin DH, Chun YS, Lee MK, Kim MS and Park JW: A novel mode of action of YC-1 in HIF inhibition: Stimulation of FIH-dependent p300 dissociation from HIF-1\{alpha\}. Mol Cancer Ther 7: 3729-3738, 2008

12. Hasanain M, Bhattacharjee A, Pandey P, Ashraf R, Singh N, Sharma S, Vishwakarma AL, Datta D, Mitra K and Sarkar J: $\alpha$-Solanine induces ROS-mediated autophagy through activation of endoplasmic reticulum stress and inhibition of Akt/mTOR pathway. Cell Death Dis 6: e1860, 2015

13. Huang X, Dai S, Dai J, Xiao Y, Bai Y, Chen B and Zhou M: Luteolin decreases invasiveness, deactivates STAT3 signaling, and reverses interleukin- 6 induced epithelial-mesenchymal transition and matrix metalloproteinase secretion of pancreatic cancer cells. OncoTargets Ther 8: 2989-3001, 2015.

14. Schulz K and Dabels J: Glucose-6-phosphate dehydrogenase of blood platelets in diseases of the thrombopoietic system. Folia haematol Int Mag Clin Morphol Blutforsch 94: 223-229, 1970 (In German).

15. Livak KJ and Schmittgen TD: Analysis of relative gene expression data using real-time quantitative PCR and the 2(-Delta Delta C(T)) method. Methods 25: 402-408, 2001.

16. Xiao B, Lin D, Zhang X, Zhang M and Zhang X: TTF1, in the form of nanoparticles, inhibits angiogenesis, cell migration and cell invasion in vitro and in vivo in human hepatoma through STAT3 regulation. Molecules 21: E1507, 2016.

17. Song H, Pan D, Sun W, Gu C, Zhang Y, Zhao P, Qi Z and Zhao S: SiRNA directed against annexin II receptor inhibits angiogenesis via suppressing MMP2 and MMP9 expression. Cell Physiol Biochem 35: 875-884, 2015.

18. Mahecha AM and Wang H: The influence of vascular endothelial growth factor-A and matrix metalloproteinase- 2 and -9 in angiogenesis, metastasis, and prognosis of endometrial cancer. OncoTargets Ther 10: 4617-4624, 2017.

19. Yao ZG, Li WH, Hua F, Cheng HX, Zhao MQ, Sun XC, Qin YJ and Li JM: LBH589 inhibits glioblastoma growth and angiogenesis through suppression of HIF-1 $\alpha$ expression. J Neuropathol Exp Neurol 76: 1000-1007, 2017.

20. John A and Tuszynski G: The role of matrix metalloproteinases in tumor angiogenesis and tumor metastasis. Pathol Oncol Res 7: 14-23, 2001.

21. Hegde PS, Wallin JJ and Mancao C: Predictive markers of anti-VEGF and emerging role of angiogenesis inhibitors as immunotherapeutics. Semin Cancer Biol, Dec 8, 2017 (Epub ahead of print).

22. Olsen JJ, Pohl SÖ, Deshmukh A, Visweswaran M, Ward NC, Arfuso F, Agostino M and Dharmarajan A: The Role of wnt signalling in angiogenesis. Clin Biochem Rev 38: 131-142, 2017. 
23. Yang JG, Wang LL and Ma DC: Effects of vascular endothelial growth factors and their receptors on megakaryocytes and platelets and related diseases. Br J Haematol 180: 321-334, 2018.

24. Kong DH, Kim MR, Jang JH, Na HJ and Lee S: A review of anti-angiogenic targets for monoclonal antibody cancer therapy. Int J Mol Sci 18: pii: E1786, 2017.

25. Dahlof B, Hansson L, Lindholm L, Rastam L, Schersten B and Wester PO: STOP-hypertension: Swedish trial in old patients with hypertension. J Hypertens 4: 511-513, 1986.

26. Lee M, Choi JY, Lim JS, Park MS, Kim MJ and Kim H: Lack of anti-tumor activity by anti-VEGF treatments in hepatic hemangiomas. Angiogenesis 19: 147-153, 2016.

27. Zachary I and Gliki G: Signaling transduction mechanisms mediating biological actions of the vascular endothelial growth factor family. Cardiovasc Res 49: 568-581, 2001.

28. Cho CH, Lee CS, Chang M, Jang IH, Kim SJ, Hwang I, Ryu SH, Lee CO and Koh GY: Localization of VEGFR-2 and PLD2 in endothelial caveolae is involved in VEGF-induced phosphorylation of MEK and ERK. Am J Physiol Heart Circ Physiol 286: H1881-1888, 2004

29. Kim BW, Choi M, Kim YS, Park H, Lee HR, Yun CO, Kim EJ, Choi JS, Kim S, Rhim H, et al: Vascular endothelial growth factor (VEGF) signaling regulates hippocampal neurons by elevation of intracellular calcium and activation of calcium/calmodulin protein kinase II and mammalian target of rapamycin. Cell Signal 20: 714-725, 2008

30. Qian BZ and Pollard JW: Macrophage diversity enhances tumor progression and metastasis. Cell 141: 39-51, 2010.

31. Attri KS, Mehla K and Singh PK: Evaluation of macrophage polarization in pancreatic cancer microenvironment under hypoxia. Methods Mol Biol 1742: 265-276, 2018.

32. Ryder M, Ghossein RA, Ricarte-Filho JC, Knauf JA and Fagin JA: Increased density of tumor-associated macrophages is associated with decreased survival in advanced thyroid cancer Endocr Relat Cancer 15: 1069-1074, 2008.

33. Gazzaniga S, Bravo AI, Guglielmotti A, van Rooijen N, Maschi F, Vecchi A, Mantovani A, Mordoh J and Wainstok R: Targeting tumor-associated macrophages and inhibition of MCP-1 reduce angiogenesis and tumor growth in a human melanoma xenograft J Invest Dermatol 127: 2031-2041, 2007.

34. Jia JB, Wang WQ, Sun HC, Zhu XD, Liu L, Zhuang PY, Zhang JB, Zhang W, Xu HX, Kong LQ, et al: High expression of macrophage colony-stimulating factor-1 receptor in peritumoral liver tissue is associated with poor outcome in hepatocellular carcinoma after curative resection. Oncologist 15: 732-743, 2010

35. Lin Y, Shi R, Wang X and Shen HM: Luteolin, a flavonoid with potential for cancer prevention and therapy. Curr Cancer Drug Targets 8: 634-646, 2008

36. Shih T and Lindley C: Bevacizumab: An angiogenesis inhibitor for the treatment of solid malignancies. Clin Ther 28: 1779-1802, 2006

37. Browne S and Pandit A: Engineered systems for therapeutic angiogenesis. Curr Opin Pharmacol 36: 34-43, 2017

38. Padwal M, Siddique I, Wu L, Tang K, Boivin F, Liu L, Robertson J, Bridgewater D, West-Mays J, Gangji A, et al: Matrix metalloproteinase 9 is associated with peritoneal membrane solute transport and induces angiogenesis through $\beta$-catenin signaling. Nephrol Dial Transplant 32: 50-61, 2017.
39. Wen Z, Huang C, Xu Y, Xiao Y, Tang L, Dai J, Sun H, Chen B and Zhou M: $\alpha$-Solanine inhibits vascular endothelial growth factor expression by down-regulating the ERK1/2-HIF-1 $\alpha$ and STAT3 signaling pathways. Eur J Pharmacol 771: 93-98, 2016.

40. Lin TH, Hsu WH, Tsai PH, Huang YT, Lin CW, Chen KC, Tsai IH, Kandaswami CC, Huang CJ, Chang GD, et al: Dietary flavonoids, luteolin and quercetin, inhibit invasion of cervical cancer by reduction of UBE2S through epithelial-mesenchymal transition signaling. Food Funct 8: 1558-1568, 2017.

41. Triantafyllou A, Mylonis I, Simos G, Bonanou S and Tsakalof A Flavonoids induce HIF-1alpha but impair its nuclear accumulation and activity. Free Radic Biol Med 44: 657-670, 2008

42. Nguyen A, Moussallieh FM, Mackay A, Cicek AE, Coca A, Chenard MP, Weingertner N, Lhermitte B, Letouzé E, Guérin E, et al: Characterization of the transcriptional and metabolic responses of pediatric high grade gliomas to mTOR-HIF-1 $\alpha$ axis inhibition. Oncotarget 8: 71597-71617, 2017.

43. Wang Q, Wang H, Jia Y, Ding H, Zhang L and Pan H: Luteolin reduces migration of human glioblastoma cell lines via inhibition of the p-IGF-1R/PI3K/AKT/mTOR signaling pathway. Oncol Lett 14: 3545-3551, 2017.

44. Liu Y, Huang J, Zheng X, Yang X, Ding Y, Fang T, Zhang Y, Wang S, Zhang X, Luo X, et al: Luteolin, a natural flavonoid, inhibits methylglyoxal induced apoptosis via the mTOR/4E-BP1 signaling pathway. Sci Rep 7: 7877, 2017.

45. Wouters BG and Koritzinsky M: Hypoxia signalling through mTOR and the unfolded protein response in cancer. Nat Rev Cancer 8: 851-864, 2008.

46. Masoud GN and Li W: HIF-1 $\alpha$ pathway: Role, regulation and intervention for cancer therapy. Acta Pharm Sin B 5: 378-389, 2015.

47. Hsu CW, Huang R, Khuc T, Shou D, Bullock J, Grooby S, Griffin S, Zou C, Little A, Astley H and Xia M: Identification of approved and investigational drugs that inhibit hypoxia-inducible factor-1 signaling. Oncotarget 7: 8172-8183, 2016.

48. Zhang Z, Amorosa LF, Coyle SM, Macor MA, Lubitz SE, Carson JL, Birnbaum MJ, Lee LY and Haimovich B: Proteolytic cleavage of AMPK $\alpha$ and intracellular MMP9 expression are both required for TLR4-mediated mTORC1 activation and HIF-1 $\alpha$ expression in leukocytes. J Immunol 195: 2452-2460, 2015.

49. Zhang K, Han ES, Dellinger TH, Lu J, Nam S, Anderson RA, Yim JH and Wen W: Cinnamon extract reduces VEGF expression via suppressing HIF-1 $\alpha$ gene expression and inhibits tumor growth in mice. Mol Carcinog 56: 436-446, 2017.

50. Reiter P: A field trial of expanded polystyrene balls for the control of Culex mosquitoes breeding in pit latrines. J Am Mosq Control Assoc 1: 519-521, 1985.

51. Chen YC, Chien LH, Huang BM, Chia YC and Chiu HF: Aqueous extracts of toona sinensis leaves inhibit renal carcinoma cell growth and migration through JAK2/stat3, Akt, MEK/ERK, and mTOR/HIF-2 $\alpha$ pathways. Nutr Cancer 68: 654-666, 2016. 